\title{
The taming of the cell: shape-memory nanopatterns direct cell orientation
}

This article was published in the following Dove Press journal:

International Journal of Nanomedicine

7 May 2014

Number of times this article has been viewed

\section{Mitsuhiro Ebara \\ Koichiro Uto \\ Naokazu Idota \\ John M Hoffman \\ Takao Aoyagi}

Biomaterials Unit, International Center for Materials Nanoarchitectonics (WPI-MANA), National Institute for Materials Science (NIMS), Namiki, Tsukuba, Japan
Correspondence: Mitsuhiro Ebara Biomaterials Unit, International Center for Materials Nanoarchitectonics (WPI-MANA), National Institute for Materials Science (NIMS),

I-I Namiki, Tsukuba, Japan

$\mathrm{Tel}+8 \mathrm{I} 298604775$

Fax +8I 298604708

Email ebara.mitsuhioro@nims.go.jp
Abstract: We report here that the direction of aligned cells on nanopatterns can be tuned to a perpendicular direction without use of any biochemical reagents. This was enabled by shapememory activation of nanopatterns that transition from a memorized temporal pattern to the original permanent pattern by heating. The thermally induced shape-memory nanopatterns were prepared by chemically crosslinking semi-crystalline poly( $\varepsilon$-caprolactone) (PCL) in a mold to show shape-memory effects over its melting temperature $\left(\mathrm{T}_{\mathrm{m}}=33^{\circ} \mathrm{C}\right)$. Permanent surface patterns were first generated by crosslinking the PCL macromonomers in a mold, and temporary surface patterns were then embossed onto the permanent patterns. The temporary surface patterns could be easily triggered to transition quickly to the permanent surface patterns by a $37^{\circ} \mathrm{C}$ heat treatment, while surface wettability was independent of temperature. To investigate the role of dynamic and reversible surface nanopatterns on cell alignment on the PCL films before and after a topographic transition, NIH 3 T3 fibroblasts were seeded on fibronectin-coated PCL films with a temporary grooved topography (grooves with a height of $300 \mathrm{~nm}$ and width of $2 \mu \mathrm{m}$ were spaced $9 \mu \mathrm{m}$ apart). Interestingly, cells did not change their direction immediately after the surface transition. However, cell alignment was gradually lost with time, and finally cells realigned parallel to the permanent grooves that emerged. The addition of a cytoskeletal inhibitor prevented realignment. These results clearly indicate that cells can sense dynamic changes in the surrounding environments and spontaneously adapt to a new environment by remodeling their cytoskeleton. These findings will serve as the basis for new development of spatiotemporal tunable materials to direct cell fate.

Keywords: shape-memory surface, poly( $\varepsilon$-caprolactone), nanopatterns, temperature-responsive polymers, cell orientation

\section{Introduction}

Adherent cells are known to probe and respond to the mechanical properties of the surrounding extracellular matrix (ECM) where they adhere and interact. ${ }^{1,2}$ In fact, cells actively deform and remodel their ECM, ${ }^{3}$ probe its rigidity and topography, ${ }^{4}$ and undergo lineage-specific differentiation by integrating various biophysical signals. ${ }^{5}$ There have been numerous reports that cells have the ability to respond to the mechanical resistivity of the substrate upon which they are grown; ${ }^{6}$ for instance, cells respond to the stiffness of their substrate by altering cytoskeletal organization, cell-substrate adhesions, and other processes important for regulating cell behavior. ${ }^{7-9}$ In addition to sensing stiffness, topographical cues also play an integral role in influencing cell fate. Arrays of parallel nanogrooves, for example, have been used as a popular nanotopography model in previous studies focused on the effects of the substratum 
nanotopography on cell function. ${ }^{10,11}$ Substrate topography can strongly influence the polarity of many different cell types through a process known as contact guidance. ${ }^{12}$ Cells can also respond to gradients in topographic cues. ${ }^{13,14}$ The cell shape and velocity are closely related to the degree of the local anisotropy of the substrate, indicating that cells could integrate orthogonally directed mechanical cues on a scale comparable to that of the feature sizes of in vivo ECM networks. In addition to proliferation and migration, the nanotopography of the cells' surroundings also plays an important role in cell differentiation. For instance, either nanopits or nanotubes stimulate osteogenic differentiation of human mesenchymal stem cells (hMSCs) in the absence of osteogenic induction media. ${ }^{15,16}$ Skeletal differentiation was also examined by exposing hMSCs to nanopillar structures of different heights, finding maximal differentiation on pillars of $15 \mathrm{~nm} .{ }^{17}$ These results suggest that cells might be exquisitely sensitive to 2-dimensional and possibly 3-dimensional variations in the ECM density and anisotropy, responding by dynamically altering the direction and function.

In spite of a considerable amount of ongoing research, however, current efforts are centered on rather static patterns. Due to the dynamic nature of the regeneration processes, static surfaces seem to be deficient in mimicking changing physiological conditions, such as would be expected during tissue repair processes such as healing. Therefore, the scientific community has recently shown increased interest in developing surfaces with tunable abilities. ${ }^{18}$ In this context, "smart" or "stimuli-responsive" materials have emerged as powerful tools for basic cell studies as well as promising biomedical applications. Recent examples of smart materials include temperature-responsive polymer-surfaces where the surface energy can be controlled with temperature. Okano et al have successfully developed dynamically switchable surfaces that exhibit temperature-responsive hydrophilic/ hydrophobic alterations with external temperature changes, which, in turn, result in thermally modulated interactions with biomolecules and cells. ${ }^{19,20}$ Yousaf et al have demonstrated an electroactive monolayer that could be switched to turn on the immobilization of ligands and subsequently promote the migration and growth of cells. ${ }^{21,22}$ A photocleavable group has been also utilized to study collective cell migration which plays a major role in cancer metastasis and wound healing. ${ }^{23}$ Concerning dynamically switchable surfaces with mechanical properties, Lam et al have developed a reconfigurable microtopography system for cell alignment using reversible wavy microfeatures on polydimethylsiloxane (PDMS). ${ }^{24}$
As an alternative approach, we propose here a shapememory cell culture platform to direct cell behavior. Although most previous work has centered on "bulk" shape memory behavior, ${ }^{25,26}$ "surface" shape memory has been also reported. ${ }^{27,28}$ We have recently reported shapememory surfaces fabricated from temperature-responsive poly( $\varepsilon$-caprolactone) (PCL) films with on-demand, tunable grooves. ${ }^{29}$ One of the great advantages of PCL over other temperature-responsive polymers is that surface properties such as wettability and charge are independent of temperature. Therefore, the surface topography can transition without changing cell-surface interactions. First, permanent nanopatterns were generated by crosslinking the PCLs in a mold. Temporary nanopatterns were later embossed into the cross-linked PCLs. The effects of dynamic changes in the nanopatterns were investigated by the application of heat; specifically, we analyzed cell alignment on the PCL films before and after the shape-memory activation, the surface of which was programmed to transition from temporary grooved nanopatterns to permanent grooved nanopatterns which are perpendicular to the original shape (Figure 1).

\section{Materials and methods}

\section{Preparation of shape-memory PCL films}

Shape-memory PCL films were prepared by crosslinking tetra-branched PCL with acrylate end-groups in the presence of linear PCL telechelic diacrylates. ${ }^{30,31}$ Briefly, two-branched and four-branched PCL were synthesized by a $\varepsilon$-caprolactone (CL) (Tokyo Kasei Kogyo Co, Ltd, Tokyo, Japan) ringopening polymerization that was initiated with tetramethylene glycol (Wako Pure Chemical Industries, Ltd, Osaka, Japan) and pentaerythritol (Tokyo Kasei Kogyo Co, Ltd) as initiators, respectively. Acryloyl chloride (Tokyo Kasei Kogyo Co, Ltd) was then reacted with the end of the branched chains. The structures and the molecular weights were estimated by nuclear magnetic resonance ( ${ }^{1} \mathrm{H}$ NMR) spectroscopy (JEOL, Tokyo, Japan) and gel permeation chromatography (JASCO International Co, Ltd, Tokyo, Japan). The obtained PCL macromonomers were dissolved in xylene containing benzoyl peroxide (BPO; Sigma-Aldrich, St Louis, MO, USA) and the solution was injected between a glass slide with a $0.2 \mathrm{~mm}$ thick Teflon spacer. The PCL macromonomers were cured for 180 minutes at $80^{\circ} \mathrm{C}$.

\section{Characterization of shape-memory PCL films}

The thermal properties of the branched PCLs were measured by differential scanning calorimetry (DSC) (6100; SEIKO 


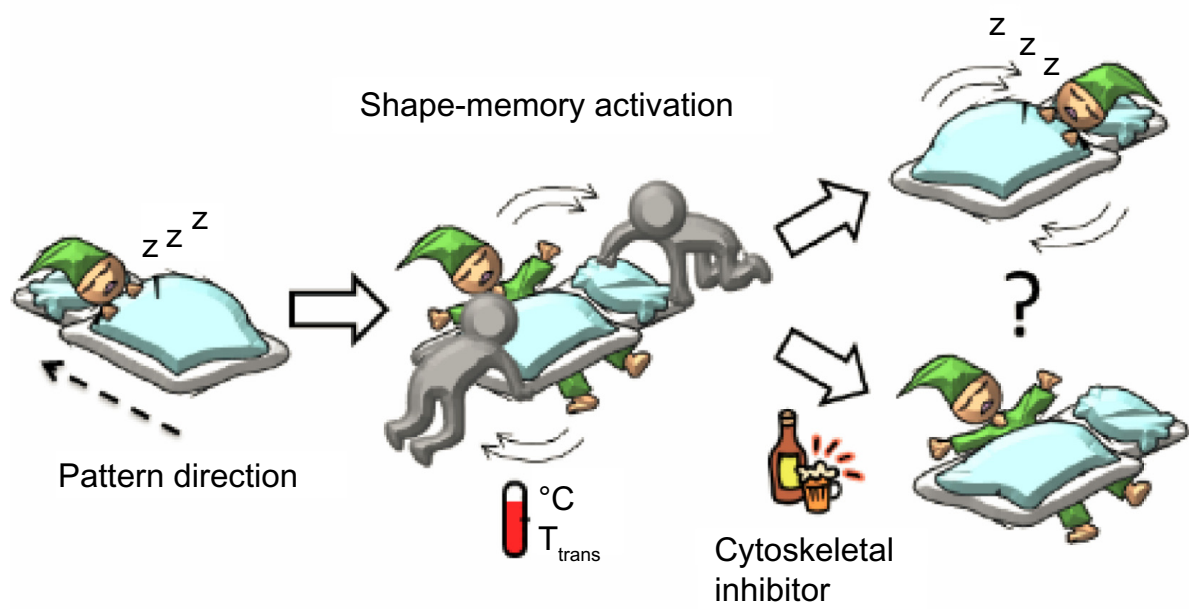

Figure I A schematic representation of cell response to the surrounding environmental changes.

Note: The figure illustrates how an aligned and elongated cell changes its morphology when the direction of surface patterns suddenly changes.

Abbreviation: $\mathrm{T}_{\text {trans' }}$, transition temperature.

Instruments Inc, Chiba, Japan). The mechanical properties of the cross-linked materials were characterized by a tensile test (EZ-S 500 N; Shimadzu Corporation, Kyoto, Japan). The shape-memory effect of the cross-linked PCL films has been quantified by thermomechanical experiments. A tensile tester equipped with a thermo chamber that allowed simultaneous strain and thermal programs was used. The experiment allowed the determination of the strain fixity rate $R_{f}$, as well as the strain recovery rate $R_{r}$. The $R_{f}$ quantifies the fixability of the temporary form. The $\mathrm{R}_{\mathrm{r}}$ describes to what extent the permanent shape is recovered.

\section{Surface shape-memory assays}

To prepare a shape-memory surface with permanent nanopatterns, the PCL macromonomer solution was cured between a nanopatterned glass mold and a flat glass slide with a $0.2 \mathrm{~mm}$ thick Teflon spacer for 180 minutes at $80^{\circ} \mathrm{C}$. Nanopatterned molding of glass substrates was performed by using an electron beam (EB) lithography system (ELS-7500EX, Elionix Inc, Tokyo, Japan). To program temporary surface patterns, the films were compressed in a thermo chamber. A compressive stress of $0.1 \mathrm{MPa}$ was applied to the samples at $37^{\circ} \mathrm{C}$, and maintained for 5 minutes. The embossing stress was then released at $4^{\circ} \mathrm{C}$ after 10 minutes of cooling. Samples had a temporary surface pattern that could be triggered to transition to the permanent surface pattern by heating. Nanopatterned PCL surfaces were observed by atomic force microscopy (AFM) (SPM-9500J3, Shimadzu Corporation) in non-contact mode using a $\mathrm{Si}_{3} \mathrm{~N}_{4}$ cantilever (spring constant; $42 \mathrm{~N} / \mathrm{m}$ ), and the sample temperature was controlled using a thermo controller. To heat nanopatterned PCL surfaces locally, the PCL film was located immediately above a microheater-integrated glass plate (Covalent Materials Corporation, Tokyo, Japan). The microheater was designed to be $25 \mu \mathrm{m}$ in line width. A direct current (DC) power source (Watty Corporation, Tokyo, Japan) was used to control the electric current flowing through the microheater. The DC power was set in the range of $1-8 \mathrm{~V}$ and was applied to the microheater for a controlled time of 10 seconds. The monitored electric current was in the range of 10-90 mA.

\section{Cell alignment assay}

Before cell cultivation, PCL samples were placed in a $32^{\circ} \mathrm{C}$ incubator for 1 hour to equilibrate with $10 \mu \mathrm{g} / \mathrm{mL}$ fibronectin. NIH 3 T3 fibroblasts were seeded at a density of $1.5 \times 10^{4}$ cells $\mathrm{cm}^{-2}$ on the temporal grooved surface (grooves with width of $2 \mu \mathrm{m}$ and a height of $300 \mathrm{~nm}$ are spaced $9 \mu \mathrm{m}$ apart) and cultured in Dulbecco's Modified Eagle's Medium in the presence of $10 \%$ fetal bovine serum (FBS) at $32^{\circ} \mathrm{C}$ for 48 hours. For the surface shape-memory experiment, the cells were transferred to a $37^{\circ} \mathrm{C}$ incubator after 6 hours of incubation at $32^{\circ} \mathrm{C}$. The cells were subjected to a $37^{\circ} \mathrm{C}$ heat treatment for 1-2 hours. The cells were then allowed to equilibrate at $32^{\circ} \mathrm{C}$ again. The cell morphology was continuously monitored and imaged using a phase contrast microscope (Olympus IX71; Olympus Corporation, Tokyo, Japan). Cell orientation angles were quantified by the analysis of phase contrast images and defined as the angle against the pattern direction. The cells were considered aligned with the grooves when this angle was less than $15^{\circ}$. Cell elongations were calculated from 
the length ratio of Y-axis (elongation direction) and $\mathrm{X}$-axis (perpendicular direction against elongation). To investigate the role of cytoskeletal structures during shape-memory experiments, cytochalasin D (Sigma-Aldrich) was used. Cells were first cultured at $32^{\circ} \mathrm{C}$ for 24 hours. The cells were subjected to a $37^{\circ} \mathrm{C}$ heat treatment for 1 hour in the presence of cytochalasin $\mathrm{D}(1 \mu \mathrm{g} / \mathrm{mL})$ and allowed to equilibrate at $32^{\circ} \mathrm{C}$ for 24 hours. The culture medium was then exchanged to remove cytochalasin D from the medium and cells were cultured for another 24 hours.

\section{Results}

\section{Modulation of shape-memory temperature}

PCL is an important class of biocompatible and biodegradable synthetic polymers ${ }^{32-34}$ which has been approved for biomedical applications by the US Food and Drug Administration (FDA). PCL is a semi-crystalline polymer that has a melting temperature $\left(\mathrm{T}_{\mathrm{m}}\right)$ above which the mobility of polymer chains changes dramatically. As the material is strained above the $\mathrm{T}_{\mathrm{m}}$, polymer chains can stretch in the direction of an applied external force because the material is in the amorphous state. This strained shape (temporary shape) can be fixed when the material is cooled below the $T_{m}$ because stretched polymer chains crystallize. If the polymer chains are chemically or physically cross-linked, the material returns to its original shape (permanent shape) by heating it again to above the $T_{m}$. During this process, an increase of entropy serves as a driving force for the material to recover its initial shape. ${ }^{25}$ Thus, the cross-linked PCL offers reversibly crystallizable regions that can fix a temporary shape and have dual-shape capability, showing shape memory effects. The relatively high $\mathrm{T}_{\mathrm{m}}$ of PCL $\left(\sim 60^{\circ} \mathrm{C}\right)$, however, has limited the potential use for biological applications. We have previously reported two different approaches to controlling the $\mathrm{T}_{\mathrm{m}}$ of PCL: (1) tailoring the branched numbers, ${ }^{29-31}$ and (2) incorporating non-crystalline segments. ${ }^{35-37}$ In this study, the branched numbers were varied because this approach can decrease the $\mathrm{T}_{\mathrm{m}}$ while retaining a sharp transition in a narrow temperature range. Two-branched and four-branched PCL were synthesized by ring-opening polymerization from tetramethylene glycol and pentaerythritol, respectively. The average degrees of polymerization of each branch in two-branched and fourbranched PCL were 18 and 10, respectively. The obtained copolymers were then reacted with acryloyl chloride to introduce vinyl groups at the end chains. The $\mathrm{T}_{\mathrm{m}}$ decreased proportionally with increasing four-branched PCL content because an increase in crosslinking density imposes restrictions on chain mobility and reduces the crystallization (data not shown). In this study, we mixed two- and four-branched PCL macromonomers at 50/50 wt $\%$ mixing ratio because it has a $\mathrm{T}_{\mathrm{m}}$ around $33^{\circ} \mathrm{C}$ and the transition occurs over a few degrees Celsius. The mixed PCL macromonomer solution containing BPO was cured for 180 minutes at $80^{\circ} \mathrm{C}$. The success of thermal curing was confirmed from the disappearance of the vinyl groups in ${ }^{1} \mathrm{H}$ NMR spectra as described previously. The bulk shape-memory properties for the cross-linked PCL samples were investigated by cyclic thermomechanical tests. The strain fixity rate $\mathrm{R}_{\mathrm{f}}$ and the strain recovery rate $\mathrm{R}_{\mathrm{r}}$ were approximately $99 \%$ and $90 \%$, respectively. The high $\mathrm{R}_{\mathrm{f}}$ and $\mathrm{R}_{\mathrm{r}}$ values indicate that the cross-linked PCL has excellent shape-memory ability.

\section{Shape-memory nanotopography}

Next, we examined the surface shape-memory effect using a PCL film. To prepare the shape-memory surfaces, PCL macromonomers were cross-linked in a master mold with permanent surface patterns. The cross-linked film was then compressed with temporary surface patterns in a thermo chamber. A compressive stress of $0.1 \mathrm{MPa}$ was applied to the samples at $37^{\circ} \mathrm{C}$ and held for 5 minutes. The embossing stress was then released at $4^{\circ} \mathrm{C}$ after 10 minutes of cooling. In the previous study, we observed that the embossed depth increased with an increase in applied stress, and the cross-sectional profiles with an applied stress of $0.1 \mathrm{MPa}$ or above were almost identical to that of the original master. ${ }^{31}$ Figure 2 shows topographic surface images of the crosslinked PCL films before and after shape-memory transition. When a PCL film with a permanent pattern (Japanese $¥ 100$ coin) was embossed with a temporary pattern (US\$1 coin) by application of pressure at $37^{\circ} \mathrm{C}$ and subsequently cooled, the film was deformed and fixed into the $\$ 1$ pattern. The temporary surface pattern was quickly erased by heating and the permanent shape, a $¥ 100$ coin in this case, was completely recovered (Figure 2A). Figure $2 \mathrm{~B}$ and $\mathrm{C}$ show topographic surface images of micropatterns with a height of $50 \mu \mathrm{m}$ observed using scanning electron microscope (SEM). First, the permanent micropatterns were fabricated on a PCL film. Then, an additional micropattern was overwritten onto the permanent pattern using an additional mold. The permanent letter "A" was replaced by the temporary number " 1 ". The temporary " 1 " was erased and recovery of the permanent "A" was achieved by heating (Figure 2B). A shape-memory transition of surface patterns was also demonstrated by local heating of the PCL film. The PCL film was located immediately above a microheater-integrated glass plate with 


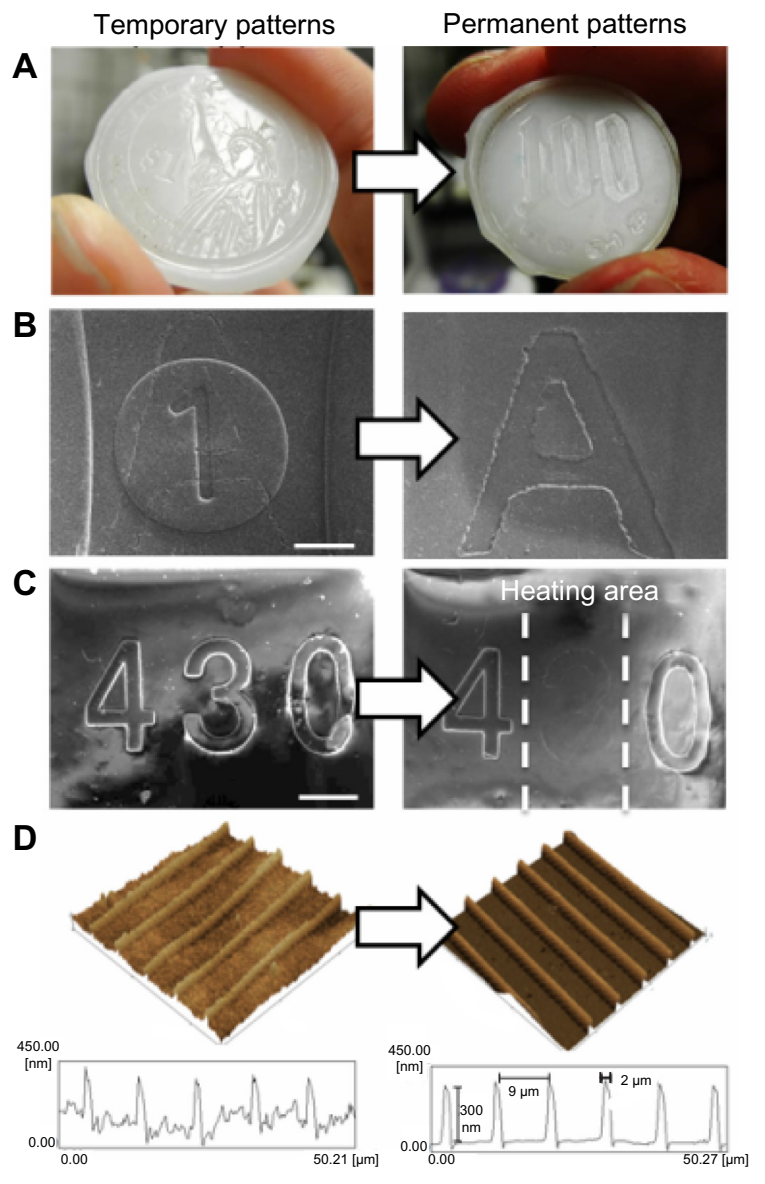

Figure 2 Shape-memory transition from a memorized temporal pattern (left) to the original permanent pattern (right).

Notes: (A) macroscopic; (B and C) SEM (bar $=1 \mathrm{~mm}$ ); and (D) AFM images of PCL films before and after shape-memory transition.

Abbreviations: SEM, scanning electron microscope; AFM, atomic force microscopy $\mathrm{PCL}$, poly( $\varepsilon$-caprolactone).

$25 \mu \mathrm{m}$ line width. A DC power source was used to control the electric current flowing through the microheater. Within 10 seconds, an area with approximately $1 \mathrm{~mm}$ in width was heated above the $\mathrm{T}_{\mathrm{m}}$ and thus, only the number in the heated area disappeared (Figure 2C). Figure 2D demonstrates the surface shape-memory transition of nanopatterns observed by AFM. First, parallel nanogrooves with a height of approximately $300 \mathrm{~nm}$ and a width of 2,000 nm were fabricated on a PCL film as a permanent shape. Then, additional nanogrooves with the same geometry were directly programmed above the $\mathrm{T}_{\mathrm{m}}$, with the temporary grooves oriented perpendicularly to the permanent grooves. Although the roughness of the temporary surface increased after cooling due to crystallization of the PCL below the $T_{m}$, the permanent nanogrooves were successfully replaced by temporary nanogrooves which were oriented $90^{\circ}$ to the permanent grooves. After shape-memory activation, the permanent nanogrooves fully recovered. Regardless of the pattern depth, therefore, the permanent pattern was found to return fully to its original shape after shape-memory activation above $\mathrm{T}_{\mathrm{m}}$.

\section{Dynamic controls of cell orientation}

To investigate the role of dynamic surface nanopatterns on cell alignment on the PCL films before and after a topographic transition, cells were cultured on the PCL films and shape-memory activation was carried out. One of the advantages of using PCL is the good cell compatibility, the wettability of which is independent of temperature (Figure 3). This is very important for the following cell culture experiment because surface wettability determines initial cell adhesion. ${ }^{38,39}$ First, NIH 3T3 fibroblasts were seeded on fibronectin-coated PCL films with a temporary grooved topography (grooves with a height of $300 \mathrm{~nm}$ and width of $2,000 \mathrm{~nm}$ were spaced $9,000 \mathrm{~nm}$ apart) and cultured at $32^{\circ} \mathrm{C}$ for 24 hours. Cells aligned parallel to the grooves as seen in Figure 4A. Temperature was then increased to $37^{\circ} \mathrm{C}$ for 1 hour to induce the surface transition of the nanogrooves to perpendicular direction. Interestingly, cells still aligned horizontally to the direction of the temporary grooves (or vertically to the permanent grooves), even though the direction of grooves transitioned $90^{\circ}$ to the temporary grooves (Figure 4B). However, cells spontaneously changed their shape with time and reoriented $90^{\circ}$ to the original direction at 48 hours after the shape-memory transition (Figure 4C). The cell alignment was also studied quantitatively by angular histograms (Figure 5). The cell orientation angles were defined as the angle against the temporary groove direction. The distribution of cell-orientation angles correlated well with the topographic features of the underlying temporary grooves before transition. The percentage of aligned cells was $86 \%$ of the original cell population. At 6 hours after shapememory transition, however, the percentage of cells aligned along the temporary direction decreased and the cell angle

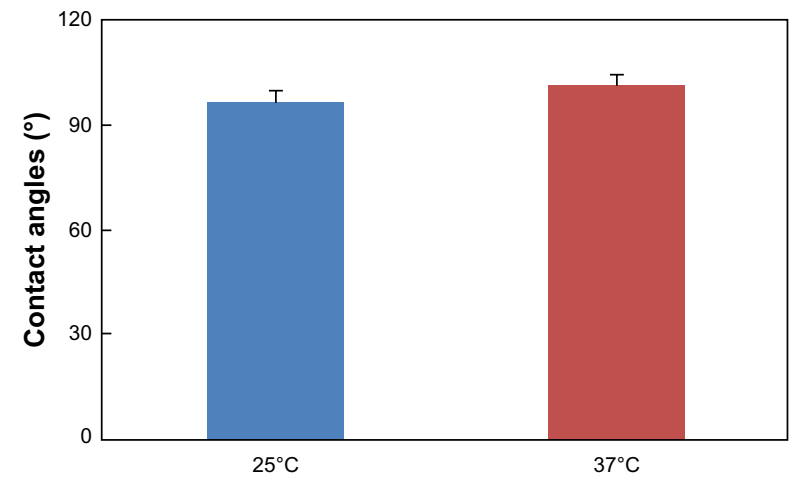

Figure 3 Contact angles on PCL surface at $25^{\circ} \mathrm{C}$ and $37^{\circ} \mathrm{C}$. Abbreviation: $\mathrm{PCL}$, poly( $\varepsilon$-caprolactone). 

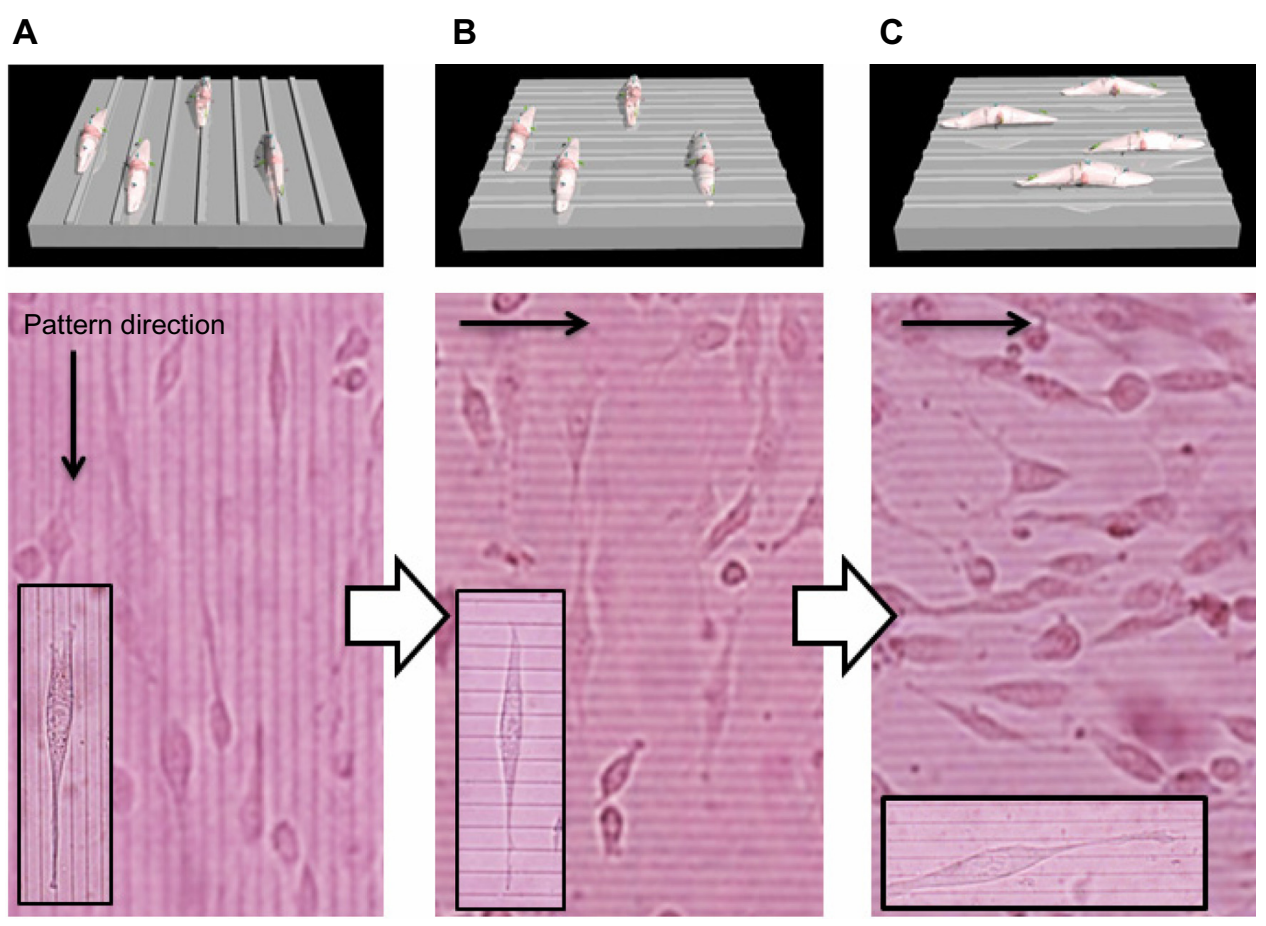

Figure 4 Phase contrast images of NIH 3 T3 fibroblasts seeded on the fibronectin-coated PCL.

Notes: (A) Phase contrast images of $\mathrm{NIH} 3 \mathrm{~T} 3$ fibroblasts seeded on the fibronectin-coated $\mathrm{PCL}$ films with the temporal grooved surface (cells were cultured at $32^{\circ} \mathrm{C}$ for 24 hours). (B) For the surface shape-memory experiment, the cells were subjected to a $37^{\circ} \mathrm{C}$ heat treatment for I hour. (C) The cells were then allowed to equilibrate at $32^{\circ} \mathrm{C}$ for 48 hours.

Abbreviation: PCL, poly( $\varepsilon$-caprolactone).

dispersion increased. After 24 hours, the percentage of cells toward the permanent direction increased, suggesting that cells reoriented themselves along the direction of the emerged permanent grooves. Seventy percent of the cells were aligned parallel to the permanent grooves after 48 hours.

To investigate the possible relationship between cell alignment and morphology, we compared the time-dependent changes in cell orientation angles with cell elongation ratio

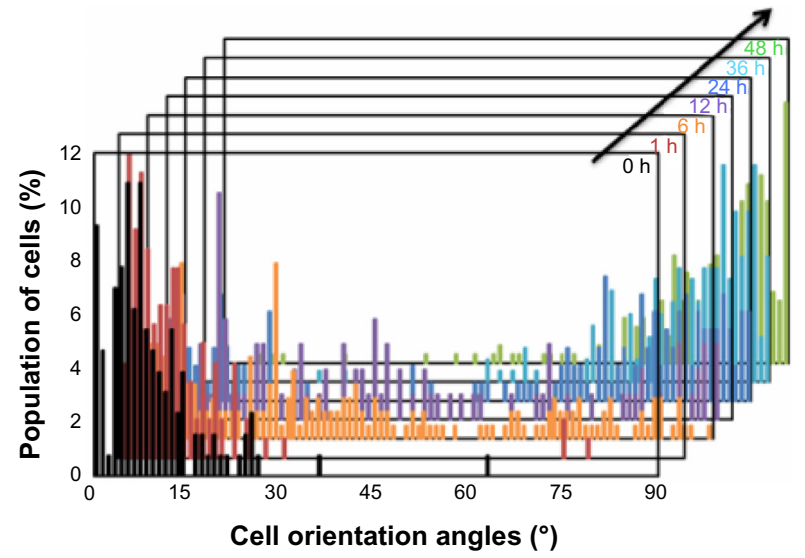

Figure 5 Histograms of cell orientation angle on the PCL film before and after shape-memory activation. Cell orientation angles were quantified by the analysis of phase contrast images and defined as the angle against the temporary groove direction.

Abbreviations: h, hours; PCL, poly( $\varepsilon$-caprolactone). after the shape-memory transition. Cell elongations were calculated from the length ratio of Y-axis (elongation direction) and $\mathrm{X}$-axis (perpendicular direction against elongation). Cells took on a more round morphology when cell alignment was lost 6 hours after shape-memory transition (Figure 6A). Cell elongation ratio, however, increased with time as cells reoriented along the direction of the emerged permanent grooves. This result indicates that cell alignment strongly correlated with cell elongation. Figure $6 \mathrm{~B}$ and $\mathrm{C}$ show timedependent changes in the orientation angles and elongation ratio of cells on the PCL film, after shape-memory transition from a temporal grooved pattern to the permanent flat surface, and from a temporal flat surface to the permanent grooved pattern, respectively. As the surface grooves disappeared, the cell angle dispersion increased and the cell elongation ratio decreased with time. On the other hand, the randomly oriented cells started to align and elongate with time as the surface grooves appeared on a flat surface.

To confirm the role of actin in regulating cell shape associated with shape-memory transition, the cells were treated with cytochalasin D, an inhibitor of actin polymerization. Cells were first cultured on temporary grooved surface at $32^{\circ} \mathrm{C}$ for 24 hours. After cells aligned along the substrate patterns, they were subjected to a $37^{\circ} \mathrm{C}$ heat treatment for 


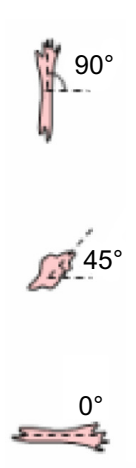

A
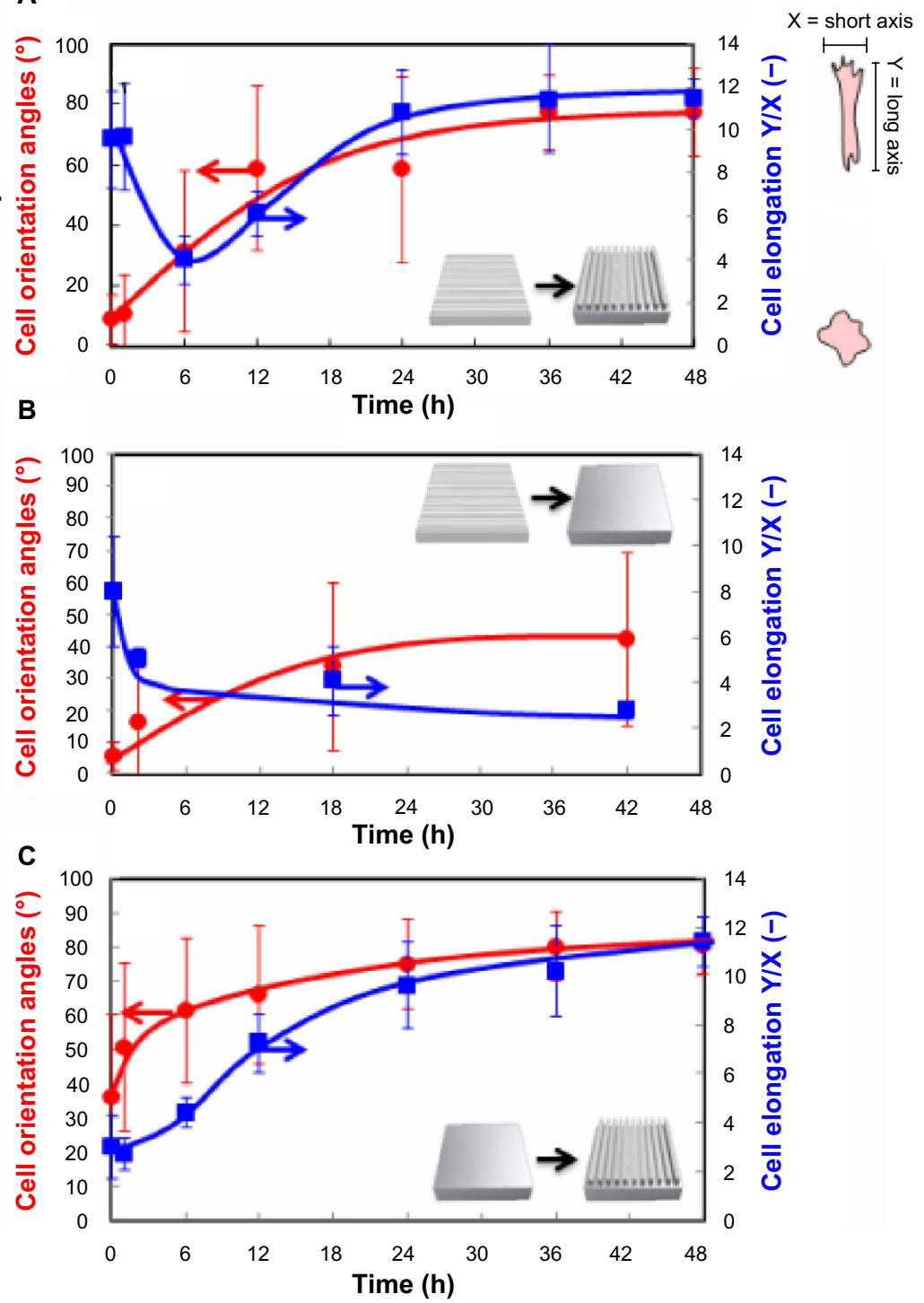

Figure 6 Time-dependent changes in the orientation angles and elongation ratio of cells on the PCL film after shape-memory transition from a temporal grooved pattern to the permanent grooved patterns which is perpendicular to the original shape (A), from a temporal grooved pattern to the permanent flat surface (B), and from a temporal flat surface to the permanent grooved pattern $(\mathbf{C})$. Cell orientation angles were quantified by the analysis of phase contrast images and defined vertical direction to elongation as a $0^{\circ}$. Cell elongations were calculated from the length ratio of $\mathrm{Y}$ axis (elongation direction) and $\mathrm{X}$ axis (perpendicular direction against elongation).

Abbreviations: h, hours; PCL, poly(e-caprolactone).

1 hour in the presence of cytochalasin D. Cells became rounded and failed to orient the permanent grooved patterns that emerged. Neither cell alignment nor elongation was observed. However, cells started to reorient and elongate along the permanent patterns after removal of cytochalasin $\mathrm{D}$ from the medium (Figure 7). The results indicate that cells sense changes in topographical features at submicron scales and respond by reorganizing their cytoskeletal proteins.

\section{Discussion}

Although numerous studies with micro- and nanoengineered substrates demonstrate influences on cell morphology, migration, proliferation, and differentiation, it remains unclear how dynamic changes in the mechanical properties influence cell behavior. One area that has seen significant progress is the fabrication of substrates that can dynamically alter their topography. Shape-memory polymers, for example, offer significant promise for the creation of topographically tunable substrates because of their capability to undergo large elastic deformations and to rapidly return to their initial undeformed state. PCL is a common choice in this regard because it is biocompatible and has a $\mathrm{T}_{\mathrm{m}}$ that can be adjusted close to physiological temperature. In this study, we prepared PCL films that had a $\mathrm{T}_{\mathrm{m}}$ around $33^{\circ} \mathrm{C}$ by 

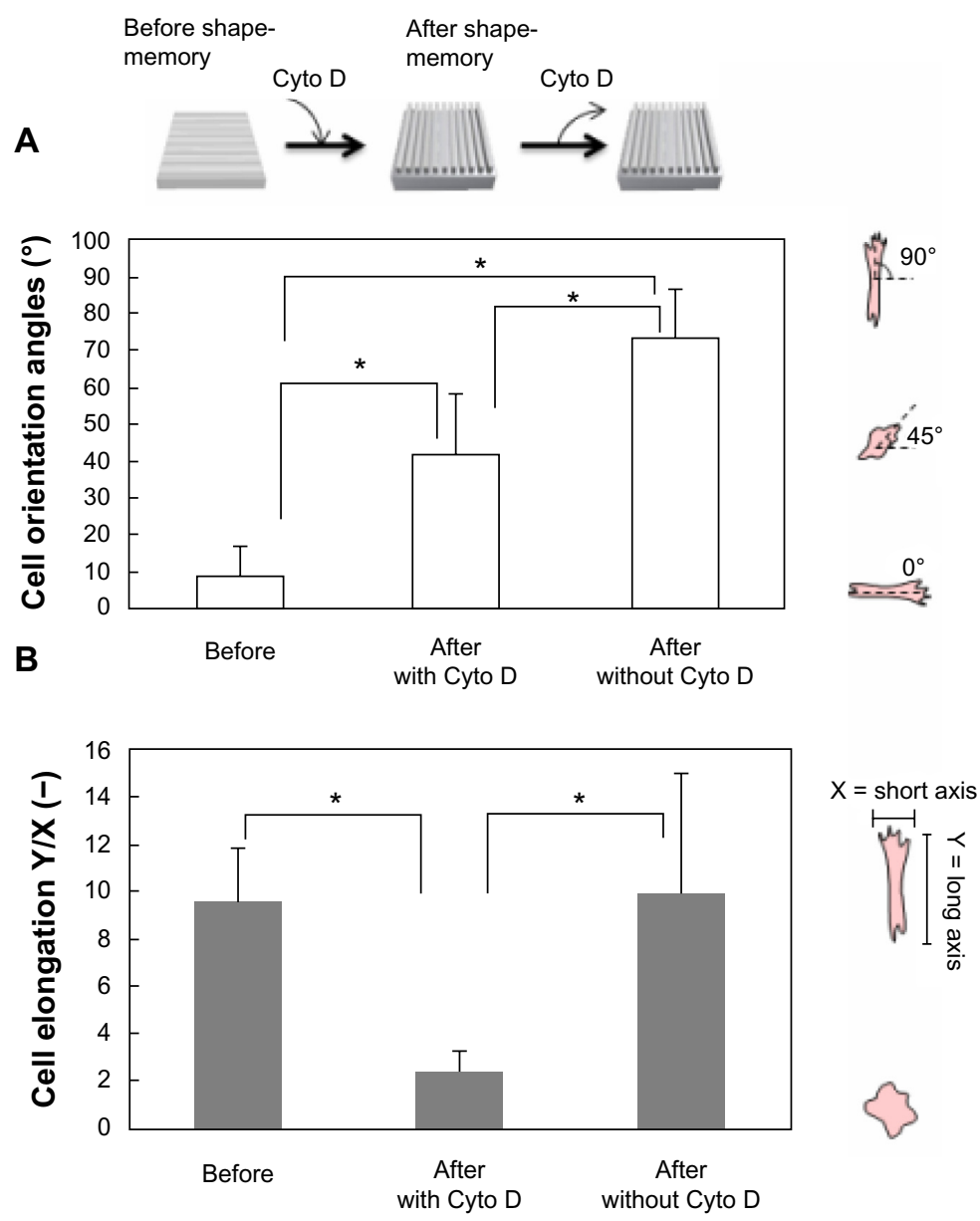

Figure 7 Cell orientation angles $(\mathbf{A})$ and elongation ratio $(\mathbf{B})$ on the $\mathrm{PCL}$ film before and after shape-memory transition from a temporal grooved pattern to the permanent grooved patterns which is perpendicular to the original shape. Cells were cultured at $32^{\circ} \mathrm{C}$ for 24 hours (left image in A). The cells were subjected to a $37^{\circ} \mathrm{C}$ heat treatment for I hour in the presence of cytochalasin D and allowed to equilibrate at $32^{\circ} \mathrm{C}$ for 24 hours (middle image in $\mathrm{A}$ ). The culture medium was then exchanged to remove cytochalasin D from the medium and cells were cultured for another 24 hours (right image in A).

introducing branching in the polymer backbone. The transition occurred over a few degrees Celsius, and the strain fixity rate and the strain recovery rate were approximately $99 \%$ and $90 \%$, respectively. In general, incorporating rigid segments or blending with other components are the most studied methods for decreasing the $\mathrm{T}_{\mathrm{m}}$ of PCL. ${ }^{40,41}$ The enthalpies $\left(\Delta \mathrm{H}_{\mathrm{m}}\right)$ observed around $\mathrm{T}_{\mathrm{m}}$, however, are diminished, because $\mathrm{T}_{\mathrm{m}}$ is reduced via the incorporation of non-PCL components that hinder crystallization. ${ }^{42}$ Figure 2 demonstrates that a temporarily memorized surface can completely recover its permanent pattern after shape-memory activation at $37^{\circ} \mathrm{C}$, regardless of pattern dimensions. These results correspond well with our previous data that the recovery of permanent surface patterns was almost $100 \% .{ }^{31}$ We have studied how the shape-memory topographical change influences cell alignment using planner PCL films with nanotopography. First, cells were seeded on fibronectin-coated PCL films with a temporary grooved topography. Cells showed marked alignment along the pattern direction. Upon heating, the direction of grooves transitioned $90^{\circ}$ to the temporary grooves. However, nearly $90 \%$ of cells still aligned horizontally to the direction of the temporary grooves at 1 hour after shape-memory transition. At 6 hours, cell angle dispersion increased and the majority of cells showed a stellate shape. The percentage of cells aligned along the vertical direction to the temporary grooves gradually increased with time, and by 36 hours $70 \%$ of cells had eventually aligned horizontally to the direction of the permanent grooves. This was not achieved when a cytoskeletal inhibitor was added because active cytoskeletal remodeling is a key determinant of cell functions including differentiation, motility, apoptosis, and proliferation. ${ }^{43,44}$ The cells did not detach or undergo apoptosis during the shapememory activation process. Figure 6 compares the timedependent changes in the orientation angles and elongation ratio of cells on the PCL film with different topographies after shape-memory transition. Of particular interest is that cells 
decreased their alignment within several hours, but it took more than 24 hours to adapt their shape to new patterns. Since there is a possibility that cells go through the mitosis during the experiment, we have also observed cell growth. Only 50\% of cells underwent cell division within the 36 hour period because cells were cultured at $32^{\circ} \mathrm{C}$ (data not shown). On the other hand, almost all cells changed their direction during the same period. These results indicate that the changes in cell alignment are mostly due to respreading of daughter cells, but some of the original cells also remodeled their cytoskeleton in response to dynamic changes in the surface topography. Although there have been previous reports that thermal activation of the substrate to restore the flat shape induced the cells to reorient randomly, ${ }^{27,28}$ we demonstrated for the first time that shape-memory nanopatterns induced a $90^{\circ}$ rotation of the cell orientation. In the future, this approach will also enable unprecedented observations of time-dependent cellsubstrate interactions, without the need for invasive forces against intact adherent cells. We believe that our finding will have a major impact on the design of synthetic cell culture substrates for the fields of not only basic cell biology but also tissue engineering; in the latter field it remains unclear how the mechanical properties of widely used biodegradable polymers influence cell behavior.

\section{Conclusion}

In conclusion, our study demonstrated that the adherent cell morphology is dynamically modulated by substratum topography. Cells cultured on the PCL film with parallel nanogrooves showed marked alignment along the pattern direction. Then, the direction of grooves was suddenly transitioned $90^{\circ}$ to the temporary grooves. Interestingly, nearly $90 \%$ of cells still aligned horizontally to the direction of the temporary grooves 1 hour after shape-memory transition. However, the percentage of cells aligned along the vertical direction to the temporary grooves gradually increased with time, and by 36 hours $70 \%$ of cells had eventually aligned horizontally to the direction of the permanent grooves. This finding is novel in that it is the first study that induced a $90^{\circ}$ rotation of the cell orientation by using a shape-memory surface. Our findings also have relevance to the interpretation of in vitro data, as well as to the study of cellular interactions with implantable biomaterials; it is yet unclear how the mechanical properties of widely used biodegradable polymers such as PCL influence cell behavior even though tissue engineering research has recently focused on the micromechanical properties of a scaffold and its effects on cells. Future work will be targeted at directing stem cell fate using the dynamically tunable nanoscale topographic features.

\section{Acknowledgments}

The authors would like to express their gratitude to the Challenging Exploratory Research grant (11018114) from the Ministry of Education, Culture, Sports, Science and Technology (MEXT), Japan. This research is also partially granted by the Japan Society for the Promotion of Science (JSPS) through the "Funding Program for World-Leading Innovative R\&D on Science and Technology (FIRST Program)," initiated by the Council for Science and Technology Policy (CSTP). The authors would like to express their gratitude to the MANA foundry for the use of clean room facilities and equipment.

\section{Disclosure}

The authors report no conflicts of interest in this work.

\section{References}

1. Discher DE, Janmey P, Wang YL. Tissue Cells Feel and Respond to the Stiffness of Their Substrate. Science. 2005;310(5751):1139-1143.

2. Reilly GC, Engler AJ. Intrinsic extracellular matrix properties regulate stem cell differentiation. J Biomech. 2010;43(1):55-62.

3. Chen Y, Dodd SJ, Tangrea MA, Emmert-Buck MR, Koretsky AP Measuring collective cell movement and extracellular matrix interactions using magnetic resonance imaging. Sci Rep. 2013;3:1879.

4. Ross AM, Jiang Z, Bastmeyer M, Lahann J. Physical Aspects of Cell Culture Substrates: Topography, Roughness, and Elasticity. Small. 2012;8(3):336-355.

5. Vincent LG, Engler AJ. Stem cell differentiation: Post-degradation forces kick in. Nat Mater. 2013;12(5):384-386.

6. Mason B, Califano J, Reinhart-King C. Matrix Stiffness: A Regulator of Cellular Behavior and Tissue Formation. In: Bhatia SK, editor. Engineering Biomaterials for Regenerative Medicine. Springer New York; 2012:19-37.

7. Chaudhuri O, Mooney DJ. Stem-cell differentiation: Anchoring cell-fate cues. Nat Mater. 2012;11(7):568-569.

8. Trappmann B, Gautrot JE, Connelly JT, et al. Extracellular-matrix tethering regulates stem-cell fate. Nat Mater. 2012;11(7):642-649.

9. Khetan S, Guvendiren M, Legant WR, Cohen DM, Chen CS, Burdick JA. Degradation-mediated cellular traction directs stem cell fate in covalently crosslinked three-dimensional hydrogels. Nat Mater. 2013;12(5):458-465.

10. Kim DH, Provenzano PP, Smith CL, Levchenko A. Matrix nanotopography as a regulator of cell function. J Cell Biol. 2012;197(3):351-360.

11. Bettinger CJ, Langer R, Borenstein JT. Engineering substrate topography at the micro- and nanoscale to control cell function. Angew Chem Int Ed Engl. 2009;48(30):5406-5415.

12. Teixeira AI, Abrams GA, Bertics PJ, Murphy CJ, Nealey PF. Epithelial contact guidance on well-defined micro- and nanostructured substrates. J Cell Sci. 2003;116(Pt 10):1881-1892.

13. Kim DH, Seo CH, Han K, Kwon KW, Levchenko A, Suh KY. Guided Cell Migration on Microtextured Substrates with Variable Local Density and Anisotropy. Adv Funct Mater. 2009;19(10):1579-1586.

14. Kim DH, Han K, Gupta K, Kwon KW, Suh KY, Levchenko A. Mechanosensitivity of fibroblast cell shape and movement to anisotropic substratum topography gradients. Biomaterials. 2009;30(29): 5433-5444. 
15. Dalby MJ, Gadegaard N, Tare R, et al. The control of human mesenchymal cell differentiation using nanoscale symmetry and disorder. Nat Mater. 2007;6(12):997-1003.

16. Oh S, Brammer KS, Li YS, et al. Stem cell fate dictated solely by altered nanotube dimension. Proc Natl Acad Sci U S A. 2009;106(7): 2130-2135

17. Sjöström T, Dalby MJ, Hart A, Tare R, Oreffo ROC, Su B. Fabrication of pillar-like titania nanostructures on titanium and their interactions with human skeletal stem cells. Acta Biomater. 2009;5(5):1433-1441.

18. Kim J, Hayward RC. Mimicking dynamic in vivo environments with stimuli-responsive materials for cell culture. Trends Biotechnol. 2012;30(8):426-439.

19. Okano T, Yamada N, Okuhara M, Sakai H, Sakurai Y. Mechanism of cell detachment from temperature-modulated, hydrophilic-hydrophobic polymer surfaces. Biomaterials. 1995;16(4):297-303.

20. Ebara M, Yamato M, Aoyagi T, Kikuchi A, Sakai K, Okano T. A novel approach to observing synergy effects of PHSRN on integrin-RGD binding using intelligent surfaces. Adv Mater. 2008;20(16):3034-3038.

21. Yousaf MN, Houseman BT, Mrksich M. Turning On Cell Migration with Electroactive Substrates. Angew Chem. 2001;113(6):1127-1130.

22. Yeo WS, Yousaf MN, Mrksich M. Dynamic interfaces between cells and surfaces: electroactive substrates that sequentially release and attach cells. J Am Chem Soc. 2003;125(49):14994-14995.

23. Rolli CG, Nakayama H, Yamaguchi K, Spatz JP, Kemkemer R, Nakanishi J. Switchable adhesive substrates: revealing geometry dependence in collective cell behavior. Biomaterials. 2012;33(8): 2409-2418.

24. Lam MT, Clem WC, Takayama S. Reversible on-demand cell alignment using reconfigurable microtopography. Biomaterials. 2008;29(11): $1705-1712$

25. Lendlein A, Langer R. Biodegradable, elastic shape-memory polymers for potential biomedical applications. Science. 2002;296(5573): 1673-1676.

26. Behl M, Razzaq MY, Lendlein A. Multifunctional shape-memory polymers. Adv Mater Weinheim. 2010;22(31):3388-3410.

27. Davis KA, Burke KA, Mather PT, Henderson JH. Dynamic cell behavior on shape memory polymer substrates. Biomaterials. 2011;32(9): 2285-2293.

28. Le DM, Kulangara K, Adler AF, Leong KW, Ashby VS. Dynamic Topographical Control of Mesenchymal Stem Cells by Culture on Responsive Poly( $\varepsilon$-caprolactone) Surfaces. Adv Mater Weinheim. 2011;23(29):3278-3283.

29. Ebara M, Uto K, Idota N, Hoffman JM, Aoyagi T. Shape-Memory Surface with Dynamically Tunable Nano-Geometry Activated by Body Heat. Adv Mater Weinheim. 2012;24(2):273-278.

30. Uto K, Yamamoto K, Hirase S, Aoyagi T. Temperature-responsive cross-linked poly( $\varepsilon$-caprolactone) membrane that functions near body temperature. J Control Release. 2006;110(2):408-413.
31. Ebara M, Uto K, Idota N, Hoffman JM, Aoyagi T. Rewritable and shapememory soft matter with dynamically tunable microchannel geometry in a biological temperature range. Soft Matter. 2013;9(11):3074-3080.

32. Pitt GG, Gratzl MM, Kimmel GL, Surles J, Sohindler A. Aliphatic polyesters II. The degradation of poly (DL-lactide), poly ( $\varepsilon$-caprolactone), and their copolymers in vivo. Biomaterials. 1981;2(4):215-220.

33. Woodward SC, Brewer PS, Moatamed F, Schindler A, Pitt CG. The intracellular degradation of poly( $(\varepsilon$-caprolactone). J Biomed Mater Res. 1985;19(4):437-444.

34. Kweon H, Yoo MK, Park IK, et al. A novel degradable polycaprolactone networks for tissue engineering. Biomaterials. 2003;24(5):801-808.

35. Miyasako H, Yamamoto K, Nakao A, Aoyagi T. Preparation of CrossLinked Poly[( $\varepsilon$-caprolactone)-co-lactide] and Biocompatibility Studies for Tissue Engineering Materials. Macromol Biosci. 2007;7(1): $76-83$.

36. Uto K, Muroya T, Okamoto M, et al. Design of super-elastic biodegradable scaffolds with longitudinally oriented microchannels and optimization of the channel size for Schwann cell migration. Sci Technol Adv Mat. 2012;13(6):064207.

37. Muroya T, Yamamoto K, Aoyagi T. Degradation of cross-linked aliphatic polyester composed of poly( $\varepsilon$-caprolactone-co-d,1-lactide) depending on the thermal properties. Polym Degrad Stab. 2009;94(3):285-290.

38. Wei J, Igarashi T, Okumori N, et al. Influence of surface wettability on competitive protein adsorption and initial attachment of osteoblasts. Biomed Mater. 2009;4(4):045002.

39. Arima $\mathrm{Y}$, Iwata $\mathrm{H}$. Effect of wettability and surface functional groups on protein adsorption and cell adhesion using well-defined mixed selfassembled monolayers. Biomaterials. 2007;28(20):3074-3082.

40. Aoyagi T, Miyata F, Nagase Y. Preparation of cross-linked aliphatic polyester and application to thermo-responsive material. $J$ Control Release. 1994;32(1):87-96.

41. Ajili SH, Ebrahimi NG. Miscibility of TPU(PCL diol $) / \mathrm{PCL}$ Blend and Its Effect on PCL Crystallinity. Macromol Symp. 2007;249-250(1): 623-627.

42. Wang Y, Rodriguez-Perez MA, Reis RL, Mano JF. Thermal and Thermomechanical Behaviour of Polycaprolactone and Starch/ Polycaprolactone Blends for Biomedical Applications. Macromol Mater Eng. 2005;290(8):792-801.

43. Ingber DE. Mechanical signaling and the cellular response to extracellular matrix in angiogenesis and cardiovascular physiology. Circ Res. 2002;91(10):877-887.

44. Silacci P, Mazzolai L, Gauci C, Stergiopulos N, Yin HL, Hayoz D. Gelsolin superfamily proteins: key regulators of cellular functions. Cell Mol Life Sci. 2004;61(19-20):2614-2623.
International Journal of Nanomedicine

\section{Publish your work in this journal}

The International Journal of Nanomedicine is an international, peerreviewed journal focusing on the application of nanotechnology in diagnostics, therapeutics, and drug delivery systems throughout the biomedical field. This journal is indexed on PubMed Central, MedLine, CAS, SciSearch ${ }^{\circledR}$, Current Contents ${ }^{\circledR} /$ Clinical Medicine,

\section{Dovepress}

Journal Citation Reports/Science Edition, EMBase, Scopus and the Elsevier Bibliographic databases. The manuscript management system is completely online and includes a very quick and fair peer-review system, which is all easy to use. Visit http://www.dovepress.com/ testimonials.php to read real quotes from published authors. 